\title{
Some interlingual communicative challenges for foreign African interpreters in South African courtrooms
}

\author{
Sam Erevbenagie Usadolo \\ Department of Communication, University of Fort Hare, South Africa. \\ Email: usadolo1@yahoo.com

\section{Ernst Kotzé} \\ Department of Applied Language Studies, Nelson Mandela Metropolitan University, South Africa \\ Email: ernst.somerstrand@gmail.com
}

\begin{abstract}
This study investigates interlingual communicative challenges faced by interpreters in South African courtrooms. Data were collected from the participants in the study by taking a qualitative approach based on the observation of courtroom proceedings, as well as unstructured and structured interviews. The interlingual challenges identified can be linked to factors such as bilingualism, dialect usage, biculturalism and the requirement of sight translation in court. Potential solutions to the problems brought about by these factors form the focal point of this study. Finally, suggestions for further research are made within the limitations of the research framework.
\end{abstract}

Keywords: bilingualism, dialect, biculturalism, sight translation, linguistic human rights

\section{Introduction}

South Africa is officially a multilingual country, hence the democratic imperative of inclusivity with regard to social factors such as religion and culture (Erasmus 1999:vii). In contrast to the past system of apartheid, the new democratic dispensation which came about in 1994 recognises in its constitution a wide spectrum of human rights, including linguistic rights. This is evident from the provisions of the new constitution in which the needs and rights of people using languages in addition to the two hitherto dominant official languages - English and Afrikaans - are recognised (South African Constitution 1996: sections 6, 30 and 31), as well as from the establishment in 2002 of the Commission for the Promotion and Protection of the Rights of Cultural, Religious and Linguistic Communities Act.

Linguistic human rights, like all other rights, are of great importance to those involved, to such an extent that when these rights are not guaranteed to groups who are linguistically handicapped with regard to the use of the dominant language(s), such groups are equally deprived of a voice 
with which to articulate and demand other human rights. The provisions mentioned above, especially as they applies to the judiciary, are clearly inviolable and sacrosanct elements of the democratic basis of the Republic of South Africa. It is therefore important that in the administration of justice, such rights be honoured in respect of speakers of the indigenous official African languages and, by extension, those of immigrant communities (cf. South African Constitution 1996: section 9(3)).

The courtroom is considered to be a sensitive social institution as matters that come before it sometimes mean the difference between freedom and captivity, or, in some countries, life and death, for the accused. This fact underscores the need for maximally effective communication between participants in the courtroom. This requirement is echoed by Khoon (1990:110), who advises that all communication in court should be handled cautiously as "[a]ny misrepresentation, be it even a verbal slip, may have dire consequences, particularly in cases where the fate of a defendant hangs in the balance".

Khoon's assertion justifies why it is necessary to bridge communication barriers between diverse language groups in the courtroom. This is carried out by providing court interpreters to assist many South Africans and others who appear before the courts and who are not proficient in the main court languages (Afrikaans and English) used during the proceedings. This is clearly stipulated in the South African Constitution which states that "[e]very accused person has a right to a fair trial, which includes the right to be tried in a language that the accused person understands; or, if that is not practicable, to have proceedings interpreted in that language" (South African Constitution 1996: section 35 [3(k)]).

There are many cases of foreign nationals who cannot speak the two main languages in South African courtrooms. Economically, South Africa is comparatively regarded as the powerhouse of Africa. This has lured foreign African migrant workers from other southern African countries, such as Zimbabwe, Botswana, Malawi, Lesotho, Zambia and Mozambique, to South Africa in search of better job opportunities. The presence of some of these immigrants in the country is not without socio-economic consequences. On a daily basis, news of the occurrence of crimes committed by foreign immigrants in South Africa is reported in the media. The observation of courtroom proceedings by one of the authors during this study showed that hardly a day passes without language-handicapped foreign immigrants being arraigned in court. This calls for a closer look at some of the challenges faced by the interpreters who are employed to bridge communication barriers between these immigrants and the court.

Although there are studies on court interpreting in South Africa, none has looked thoroughly at issues of foreign court interpreters, especially foreign African court interpreters. A study by Moeketsi (1999), for example, contains a passing reference to foreign African interpreters but does not go into detail regarding the challenges they face. A comprehensive study is therefore necessary which looks at the challenges faced by foreign African interpreters, especially given the emphasis on linguistic human rights in the South African Constitution. It is the aim of this paper to contribute in this regard by highlighting some interlingual communicative challenges faced by foreign African court interpreters and the consequences for the judicial system in South Africa. It is hoped that the results reported in this study will focus the attention of individuals and agencies involved in order for the aims of the Constitution to be achieved in this regard. 


\section{Methodology}

A qualitative approach was taken in this study, which mainly involved observations of proceedings in open courtroom sessions in order to establish the communicative roles of the main actors such as the magistrate, the prosecutor, the court interpreter and the attorneys. Unstructured and structured interviews were also used to collect data and, at times, were supported by post-data collection interviews to verify and, if necessary, clarify some of the data collected in this way.

The participants in this study were firstly foreign African court interpreters from some African countries who operate in the magistrate courts of central Johannesburg, Germiston and Hillbrow in South Africa (see reference to these countries below). Other participants included magistrates, prosecutors, attorneys and chief interpreters in the aforementioned courts. For the purpose of sampling, all foreign African court interpreters in these magistrate courts constituted the target population for investigation. Since it was evidently not possible to gain access to the population as a whole, the study had to be based on a statistically justifiable representative sample of the population; the results of the study were then extrapolated to the entire population. Sampling for a purpose such as this is then, in essence, a "[...] process of selecting just a small group of people from a large group [...]" (Walliman 2006:75) according to principles of representation which will be explained below.

Purposive sampling was used to select the foreign African interpreters. According to Aldridge and Levine (2001:80), researchers use purposive sampling to select subjects with characteristics they consider relevant to their study. Some of the characteristics that informed the selection of the interpreters in this study were the age of the interpreters (not younger than 21 years), in order to comply with ethical considerations of our affiliated institutions (University of Fort Hare, Alice and Nelson Mandela Metropolitan University, Port Elizabeth), years of experience which, for instance, should not be less than two years (an assumed minimum period to have been exposed to a range of typical court cases), and the number of regular appearances in court. Age was emphasised in order to complement the requirement of experience. This means that even if the interpreters have been practising at a much younger age, by the age of 21 they must have acquired the required experience as day-to-day practising casual interpreters. As the foreign African interpreters work on a casual basis, it means there might be some who do not work on a regular basis. We focused on those who work as foreign African court interpreters on a daily basis as we believe they would be in a better position to respond to the issues addressed in our study.

The next method used was snowball sampling which is used to identify subjects through the process of referral (O'Leary 2005:94). Snowball sampling was also used to select magistrates and prosecutors who were respondents in this study. Each court has a chief interpreter who handles the affairs of the rest of the interpreters. It was noticed during this study that in some cases, one chief interpreter's line of authority cuts across many magistrate courts in close proximity. Thus, no sampling was done in the selection of the three identified chief interpreters in the magistrate courts mentioned.

For the purpose of this study, the sample selected comprised 30 foreign African court interpreters from Nigeria, Zambia, Zimbabwe, Ghana, Mozambique, Malawi, the Democratic Republic of the Congo (DRC), Tanzania and Somalia. In addition, a total of 10 magistrates, 10 
prosecutors and 10 attorneys were sampled. The foreign African court interpreters who were participants in this study had worked between six and 10 years as non-permanent members of staff of the Department of Justice and Constitutional Development (DoJCD) of South Africa. The data analysed in this study were from interviews and observations of court proceedings. The actual data analysis began by categorising the data after which we were able to analyse all data in relation to the identified conceptual framework. Some of the concepts that came to the fore during the analytical process include bilingualism, dialects, biculturalism and sight translation, and, as such, are the focus of our analysis. We refer to these concepts as "interlingual communicative challenges" and they will be addressed in the subsequent sections.

\section{Bilingualism}

In the courtrooms that were investigated in this study, past experience is not taken into consideration by the court authorities in the employment of court interpreters, nor is any effort made to train them after they have been employed. The data in this study are illustrative of the fact that the only requirement for the employment of foreign African court interpreters is individual bilingualism. Ideally, this should mean a balanced bilingual or "a person who speaks, reads or understands two languages equally" (Richards and Schmidt 2002:51). This is a general assumption about the interpreters who claim to be bilingual in this study. It may explain why, during the process of employment, no effort is made to check their proficiency in both languages that they claim to understand or speak. Bilingualism is problematic when considered in this fashion because, as noted by Richards and Schmidt (2002:51), a bilingual in most cases "has a better knowledge of one language than another". Some interesting examples given by the authors in this regard are that the person:

- may be able to read and write in one language but not in the other;

- uses the languages in different types of situations or domains, e.g. one language at home and another at work, and

- uses one language for talking about school life and the other for talking about personal feelings.

(Richards and Schmidt 2002:51)

These characteristics reflect the bilingual nature of most of the interpreters who were respondents to questions asked to test their bilingualism in this study. Most of them $(80 \%$ $[\mathrm{N}=24])$ said they interpret from English into more than one other language. Some $(60 \%$ $[\mathrm{N}=18]$ ) said they did not study the languages or the dialects in which they interpret in court, but do understand them because they once lived in a speech community in which the languages are spoken, while only $53 \%(\mathrm{~N}=20)$ claimed they studied their mother tongues at school. When the extent to which the respondents had studied the languages was considered, it was found that only $17 \%(\mathrm{~N}=5)$ had studied the language up to primary school level, $47 \%(\mathrm{~N}=14)$ up to secondary school and $23 \%(\mathrm{~N}=7)$ up to tertiary level.

This study shows that $80 \%(\mathrm{~N}=24)$ of the interpreters interpret from English into two or more languages, while $60 \%(\mathrm{~N}=18)$ interpret into other languages besides their mother tongues. Those who interpret into languages which are not their mother tongues reported that they once lived in communities in which these languages are spoken. This is insufficient to achieve the "balanced" bilingualism required for, amongst other things, quality interpreting. 
Not even balanced bilingualism is enough to guarantee accurate and quality interpreting. According to Driesen (2003:113), bilingualism should be complemented by a "relevant linguistic and cultural background and acquired forensic knowledge". This is the only way an interpreter will be professional enough to "be able to contribute to a fair trial" in order to realise the noble objectives of the profession (Driesen 2003:113).

Besides bilingualism, Hewitt and Lee (1996) maintain that cognitive abilities are essential to practise as an interpreter. They add that, in order for an interpreter "to correctly render rotefacts (like numbers and names), the interpreter must pay close attention to detail, while listening, and then conserve the detail for a later recall with an excellent short-term memory". For Schweda-Nicholson (1989:712), other elements which play a vital role in the improvement of interpreters' skills, in addition to bilingualism, are "personality, flexibility of mind, the ability to think on one's feet and to analyse quickly, broad general knowledge, a fair level of education and cultural awareness [...]".

\section{Dialect}

One of the daily difficulties court interpreters encounter is the need to interpret new words, terms or concepts they have never heard before. For example, an interpreter in the Johannesburg Magistrate's Court, who wishes to remain anonymous, stated the following in an unstructured interview used in the study: "Oftentimes, the accused used words which at times may be familiar, at times strange, and these accused are the ones using their dialects or mixing their dialect with the standard language we interpret". Many of the respondents said that this is a recurring experience in their practice as court interpreters, and we witnessed it likewise in some of our observations of court proceedings.

On three occasions, one of the interpreters pointed out that the so-called "new words" referred to by the interpreter quoted above are new because they are words from a dialect of which he does not have complete mastery. Although $93 \%(\mathrm{~N}=28)$ of the interpreters claimed that they understood the dialects of their languages, in our post-data collection interview with $67 \%$ $(\mathrm{N}=20)$ of the interpreters, we discovered that the occurrence of strange words was a familiar problem to other interpreters whose languages have dialect(s).

A dialect is "a speech variety within a language" (De Jongh 1992:67). De Jongh elaborates by saying that "[w] hen a language is spoken by a large number of people who live in an extensive area where groups have often been isolated from one another, as in the case of Spanish and English, there will be dialectal diversity due to the geographical spread of the language" (De Jongh 1992:67). This perfectly explains the dialect situation in Nigeria with regard to Yoruba and Igbo - two languages commonly interpreted for accused persons or witnesses in South African courtrooms. Yoruba and Igbo have dominant varieties, or standard dialects, and it is assumed that all Yoruba-speaking and Igbo-speaking persons understand them. Igbo is spoken in five states in Nigeria, while Yoruba is spoken in seven. In addition to the standard dialects of the two languages, there are other dialects specific to each state, and in some states even more than one dialect is to be found.

The data collected on dialects in this study, through one unstructured interview and several structured interviews, indicate that $100 \%(\mathrm{~N}=30)$ of respondents' working languages have 
dialects and that $93 \%(\mathrm{~N}=28)$ said they understood the dialects of their languages, while $7 \%$ $(\mathrm{N}=2)$ said they did not.

In light of the fact that these different dialects or varieties have common standard dialects, one would expect that the differences between the varieties had reduced or that there would be dialect levelling, which would consequently render the impact of dialects negligible in any communicative encounter. Dialect levelling is a "process through which dialect differences become reduced" (Richards and Schmidt 2002:155) as a result of the influence of standard or dominant dialects. From our experience as researchers, apart from the fact that there are Igbospeaking interpreters and Yoruba-speaking interpreters who do not understand the standard dialects of their languages, these speakers are also influenced by their own dialects in the manner in which they use the standard dialects.

The local dialects or varieties in these different states significantly influence the way standard Igbo is spoken in each of those states. For example, in our observation in the courtroom, we witnessed two scenarios where the court interpreters had difficulties in understanding or even knowing the meaning of some of the words uttered by the accused. It was, however, not a case of unknown vocabularies as, according to the court interpreter, the words were familiar but it was difficult to find the appropriate equivalents. The words used by the accused in this particular instance and which caused a problem for the court interpreter were Ka kunu me? ('How are you people?'). The court interpreter had to request that the accused repeat the sentence in the Nigerian lingua franca - Pidgin English - before she was able to render the sentence in the target language. During the lunch break, we had to consult another Igbospeaking interpreter telephonically who confirmed the meaning as stated in Pidgin English by the accused. The person whom we consulted told us the words were specific to a variety of Igbo spoken in Asaba in Nigeria's Delta State. The sentence Ka kunu me in Asaba Igbo's dialect, called Enuani, has to be rendered as Ele otu unu mere in the general or standard dialect.

The scenario discussed regarding the Igbo standard dialect and its various dialects applies similarly to Yoruba. One of the interpreters told us he was shocked that an accused who came from the same Nigerian state spoke a Yoruba dialect which he could not interpret easily, and he had to request that the accused use the standard dialect. The interpreter maintained that, even when the accused was using the standard Yoruba dialect, the former noticed that the latter was code-mixing (mixing the standard and regional dialects together in a sentence). Code-mixing refers to intrasentential switching or mixing of various linguistic elements from a related or distinct language within the same sentence (Myers-Scotton 1993:4). The scenario depicted here is interesting because the court interpreter was surprised that both of them (the accused and interpreter) were from the same state, but the accused was speaking a dialect which the interpreter had never before heard.

A further point of interest is the assumption of dialect levelling between the standard Yoruba spoken by the court interpreter and the accused's dialect, given that both standard Yoruba and the dialect are used interchangeably in the same state. This assumption - that differences between the dialects would be levelled out - proved to be unfounded, however, since the interpreter claimed he struggled to understand the dialect of the accused.

Problems caused by an inability to understand dialects of the standard form of a language may be aggravated when it is a dialect of a cross-border language and the interpreter is not from the same side of the border where the dialect is spoken. In the case of the Igbo and Yoruba dialects 
mentioned above, the Yoruba and Igbo interpreters may not have had any socio-cultural challenges to contend with as the dialects are from closely-related speech communities influenced by the same socio-cultural issues within the same country.

This may not be the case for an interpreter who interprets for an accused across the border, whose dialect may have some "foreign" socio-cultural characteristics with which the interpreter has to contend. The challenge of lexical equivalence applies in the case of countries that share the same language but differ in their legal systems and orthographies. For example, Malawian Sena, which follows English orthography as Malawi is an Anglophone country, is different from Mozambican Sena, which follows Portuguese orthography as Mozambique is a Lusophone country. ${ }^{1}$ These differences affect the wording of legal texts and this requires the interpreter to be conversant with both legal systems. This ability is rare in South African courtrooms as all sampled cross-border language interpreters in this study said they were not conversant with the legal systems of the other country, the language of which they interpret.

In addition to the difficulties court interpreters experience with dialects, it is also a challenge to find equivalents for certain English words in various African immigrant languages and vice versa. The interpreters reported that the lack of equivalents often forced them to resort to sentence-long descriptions, explanations or circumlocutions in the target language (TL). For example, the word ozẹa in Edo does not have any English equivalent and is translated in an Edo-English dictionary by Agheyisi (1986:124) as "a sticky and unanticipated problem". In court, this word was simply interpreted as "problem" in English by the interpreter, thereby reducing the semantic effect of the word and/or not conveying in the TL the intention behind the spoken word as used by the source language (SL) speaker. These constitute examples of how dialects pose challenges to foreign African interpreters in the courtrooms. Further challenges faced by foreign African interpreters in the form of biculturalism are discussed in the following section.

\section{Biculturalism}

Biculturalism refers to the "ability to interpret experiences in the manner appropriate to both cultures involved" (De Jongh 1992:59). This requires significant cross-cultural awareness. The data in this study reveal some important facts about the respondents in this regard. For example, most of the interpreters are involved in cross-border language interpreting, their languages have dialects, and most of the languages in which they interpret are not their mother tongues but the languages learnt in the speech communities in which they once lived. This calls into question their level of cross-cultural awareness or experience appropriate for biculturalism in interpreting.

According to De Jongh (1992:59), a good interpretation means "a deep familiarity with the languages involved (bilingualism) and their respective cultures (biculturalism)". Besides bilingualism, cultural awareness is one of the vital requirements for a competent interpreter and this requires a balanced perspective of both the SL and TL cultures. The opposite of this, according to De Jongh (1992:59), could be regarded as being ethnocentric or constituting monocultural interpreting. This takes place in total disregard of the cultural contexts of the languages involved.

\footnotetext{
1 "Lusophone country" is used here to refer to a Portuguese-speaking country in which Portuguese is the official language.
} 
The influence of culture on language cannot be overemphasised and interpreting, which takes place in order to reduce language barriers between two individuals or groups, must be viewed from this perspective. Wiersinga (2003:47) states that "[ $t]$ he ability to interpret language codes and the ability to accomplish translation is partly a question of culture. Knowing how to render meaning within the prevailing cultural patterns is the ultimate way of bestowing real meaning at all levels".

For some scholars, knowledge of the culture of the interpreter's working languages is a nonnegotiable skill. Katschinka (2003:93), for instance, who discusses the set of skills legal interpreters must possess, states that "[...] knowledge of the culture and the legal system of the countries of the working languages" should be one of the core competences of legal interpreters.

Many of the variables which came to the fore in the data collected for this study underpin the importance of bicultural knowledge (or the lack thereof). For example, 93\% ( $=28)$ of the respondents in this study reported that their working languages have dialects. Although they all claimed to understand the dialects of their working languages (as discussed in section 4), certain sub-cultural challenges linked to the sociolinguistic context of dialects pose major problems to those interpreters whose working languages are not their mother tongues. This is an even larger concern for interpreters whose working languages are cross-border languages as, while they may understand the dialect(s) on their side of the border, a lack of understanding of those on the other side of the border, together with the socio-cultural factors influencing their use, will jeopardise unfettered communication between the relevant parties in court.

One of the ways the effect of this type of ignorance can be mitigated is to allow the interpreter sufficient time to interview the accused/witness as part of his/her preparation for the beginning of the trial (Grabau 1996). During the course of the interview, the interpreter should be able to determine the dialects, types of jargon, regionalisms and colloquial expressions of the accused/witness, as well as to confirm his/her level of education. Prior knowledge of these facts would, amongst other things, enable the interpreter to eliminate any possible misunderstanding as a result of dialect variation.

If it becomes clear that these factors will present an insurmountable challenge, the interpreter should, in good conscience or as is required by the code of ethics of his/her profession, withdraw from the case.

Furthermore, an exploratory interview of this nature should provide the interpreter with what De Jongh (1992:28) refers to as "sufficient referential knowledge". Apart from allowing the interpreter enough time to interview the accused/witness, De Jongh suggests that the interpreter should be given sufficient information about the "situation or subject matter" of the case, or else the "interpreter may not possess the minimum level of knowledge that enables a person to interpret, that is, to understand".

Our interaction with the foreign African court interpreters, after observing their participation in court proceedings, showed that such interpreters are not given the necessary information in advance regarding the nature of their interpreting assignments. The interpreters' responses to the question "Are you always given as much information as possible in advance regarding the nature of the interpreting assignment before your first court appearance in a case?" confirmed our observation; almost all the respondents $(90 \%[\mathrm{~N}=27])$ responded negatively to this question, 
whereas $53 \%(\mathrm{~N}=16)$ claimed that they were aware that there is a provision that they have to determine the language ability of the accused, but this is done only a few minutes before the case begins.

Our observation in the court confirms this response, but this conversation mostly took place in what could be regarded as a transient moment, barely sufficient to gather any useful information about the language background of the accused, let alone constitute the necessary preparation by the interpreter. When some of the interpreters were asked what the content of their discussion was with the accused, their responses did not relate in any way to background knowledge regarding the language ability of the accused. Some said they would introduce themselves to the accused persons as their interpreters for the case, while others said they would tell the accused not to feel intimidated in answering any question put to him/her.

Sufficient information about the case would enable the interpreter to determine what is important to discover in the pre-trial interview with the accused. As this is not done by foreign African interpreters, the rendition of the SL (and all its nuances) into the TL may be a serious problem, as described above.

\section{Sight translation}

Sight translation involves the rendering of written material in one language into an oral version in another language; on the other hand, it may also refer to "oral translation of a written document" (Gonzalez, Vasquez and Mikkelson 1991:401). On a daily basis in South African courtrooms, court interpreters sight translate charge sheets into the accused person's language.

Our observation of court proceedings, especially at the beginning of trials, shows that all charge sheets were sight translated into the accused's language. Furthermore, $60 \%(\mathrm{~N}=18)$ of the court interpreters in this study reported that they had also sight translated other documents on several occasions, either from the language of the accused or witness, into the official language used in court, or vice versa. This makes sight translation skills imperative for court interpreters. Such skills, as stated by Ostarhild (2001), should enable the court interpreters to have "a quick grasp of the meaning of the written text and a high degree of linguistic flexibility to produce almost immediately an accurate, lucid and fluently spoken version, translated at sight from the text".

Sight translation requires specific skills, some of which have to be taught through specialised educational programmes, such as reading and comprehension skills. In addition, a sight translator needs to have insight into both linguistic and sociolinguistic aspects of communication. The data collected, however, do not indicate that participants in this study have (at least formally) acquired these skills, as $73 \%(\mathrm{~N}=22)$ of them have less than a tertiary degree, and $64 \%(\mathrm{~N}=20)$ of those who claimed to have studied their working languages at school had only reached either primary school or secondary school level.

It also emerged in this study that what participants regarded as "language studied at school" (e.g. English) was in fact the medium of instruction. None of the $7 \%(\mathrm{~N}=2)$ who said they had studied a language at tertiary level had obtained his/her diploma or degree in language-related fields. 
In addition to this, the data show that $84 \%(\mathrm{~N}=25)$ of the interpreters had not been given any form of continuous professional development (CPD) training. It is highly unlikely that they would be trained, as present DoJCD policy makes no provision for CPD for foreign interpreters, even though quite a number of them have been working in the Department for several years. This means that the quality of sight translation currently practised in the DoJCD leaves much to be desired. Ostarhild (2001) warns that "[s]ight translation is not an easy skill to acquire", adding that the skills come about through "training, practice and knowledge of the process of producing sight translations from written texts".

Possible problems interpreters working with cross-border languages may encounter during sight translation can be mitigated when sight translators have knowledge of the two cultures of his/her working languages - that is, the cultures of the SL and the TL (Ostarhild 2001). Ostarhild further points out that in order to be able to access written texts quickly, it is essential for the interpreter to have an adequate understanding of the structures and syntax of the two languages.

As indicated earlier, some court interpreters interpret in cross-border languages for accused persons hailing from countries with different sociolinguistic backgrounds. In this regard, the first problem is that, due to the different backgrounds, the court interpreters may not be adequately informed about the societies and cultures of the accused persons, especially when (in the case mentioned) the accused is from a Lusophone country and the court interpreter from an Anglophone country. Secondly, this may also extend to the fact that, because of orthographical differences between, for instance, Malawian Sena (which reflects English orthography) and Mozambican Sena (which reflects Portuguese orthography), interpreters may have problems accessing written texts quickly.

Related to this is prediction, which is also important in sight translation and an important strategy when used in interpreting. In this regard, González et al. (1991:403) maintain that "[i]nterpreters are able to predict the outcome of an incomplete message because of their knowledge of the syntax and style, as well as other sociolinguistic factors in the SL culture". This requires professional training, which foreign African court interpreters do not have, and may not have even in the near future, given the low levels of education and lack of exposure to in-service training.

Interpreting is a complex task, and it is even more complex when no attempt is made to alleviate some of the problems the court interpreters may encounter. As discussed, there is no doubt that the participants (interpreters) in this study may experience problems of linguistic comprehension, due to their low levels of education or irrelevant qualifications. Thus, they may not have the appropriate knowledge of the phonology, sentence structure and semantics of the $\mathrm{SL}$; and, in the case of cross-border languages, the interpreter may have problems with the culture and sociolinguistic conventions of the accused hailing from the "other" side of the border.

These problems have to be addressed in order to ensure a fair process in the dispensation of justice. A first step, in the present circumstances, would be to make the documents available in advance to the interpreter so that the former may be sight translated. In addition to empowering the interpreter in terms of the appropriate background knowledge, this would enable him/her to decipher illegible handwriting in the case of hand-written documents. The interpreter would 
then be able to study the document and possibly consult the author for an explanation of the aspects he/she finds difficult to decipher.

If the author is unavailable, the interpreter may consult other interpreters for assistance, and, in the worst-case scenario, may have to decline the assignment or bring to the notice of the court that the document contains indecipherable parts. Unfortunately, all this is currently impossible. The data in this study have shown that $73 \%(\mathrm{~N}=21)$ of the interpreters have never been provided with the documents they are required to sight translate in advance. Worse still, the interpreters are discouraged to decline interpreting assignments, even if they feel they are unable to handle them. Faced with these shortcomings, the foreign African interpreter cannot attain the optimum quality of interpreting, which Moser-Mercer (1996:44) refers to as an ability to provide a complete and accurate rendition of the original message, and ability to capture all extralinguistic information that the speaker might have intended. The negative consequences of these shortcomings will be on the quality of the service rendered by foreign African court interpreters and the proper administration of justice.

\section{Limitation of the study}

The research was conducted in courtrooms in Johannesburg and Germiston. For a complete and comprehensive study, it would have been necessary to widen the scope to include courtrooms across all of the provinces in South Africa. We acknowledge that this is a limitation to this study, hence generalising the findings should be carried out with caution.

We are aware that the majority of the interpreters who took part in this study mentioned that oftentimes they are called to work in other courtrooms in other provinces, and thus one may conclude that these challenges will feature in their work as well. However, we recommend that instead of making such a simplistic conclusion, the findings here should be used as a possible gauge towards a similar study in other provinces.

\section{Conclusion}

This study has analysed some interlingual communicative challenges faced by interpreters in South African courtrooms. The identified interlingual challenges are related to bilingualism, dialect, biculturalism and sight translation. Given the data analysed, it was pointed out that bilingualism is a challenge to court interpreters, as they may not have the balanced bilingualism required to interpret interlingually. In addition, it was noted that the interpreters are employed simply because they are bilingual and thus cannot be assumed to be balanced bilinguals. As discussed, even if this were to be the case, quality interpreting requires more than just balanced interpreting; it requires relevant cultural and forensic knowledge.

The phenomenon of dialect, as discussed, presents daily difficulties for the court interpreters. One of the ways to mitigate its challenges is for interpreters to interpret appropriately as if there is no dialect difference. The data discussed in this study show that this is not the case. The same is true of biculturalism. The interpreters do not have cross-cultural knowledge because, according to the data analysed, some of the interpreters understand and speak the language of a community they have not lived in for a long time, hence they will not know about the community's culture. Many mitigating factors of problems related to biculturalism, such as pre- 
trial interviews with the accused and the provision of necessary information about the interpreting assignment, are not properly, if at all, carried out.

Finally, regarding sight translation, it was stated in the study that it requires specific skills, such as reading and comprehension and insight into both sociolinguistic and paralinguistic issues of the languages involved in order to ensure quality interpreting.

\section{References}

Agheyisi, R.N. 1986. An Edo-English dictionary. Benin City: Ethiope Publishing Corporation.

Aldridge, A. and K. Levine. 2001. Surveying the social world: Principles and practices in survey research. Buckingham: Open University Press.

Commission for the Promotion and Protection of the Rights of Cultural, Religious and Linguistic Communities Act, 2002.

De Jongh, E.M. 1992. An introduction to court interpreting (Theory and practice). Lanham: University Press of America.

Driesen, C. 2003. Professional ethics. In E. Hertog (ed.) Aequalitas: Equal access to justice across language and culture in the EU. Antwerp: Lessius Hogeschool. pp. 69-72.

Erasmus, M. 1999. Preface. In M. Erasmus, L. Mathibela, E. Hertog and A. Hugo (eds.) Liaison interpreting in the community. Pretoria: Van Schaik. pp. v-vii.

Gonzalez, R.D., V.E. Vasquez and H. Mikkelson. 1991. Fundamentals of court interpretation (Theory, policy, and practice). Durham, NC: Carolina Academic Press.

Grabau, C.M. 1996. Court interpreting: View from the bench. State Court Journal 20(1): 6-11.

Hewitt, W.E and R.J. Lee.1996. Behind the language barrier, or 'You say you were eating an orange?' State Court Journal 20(1): 23-31.

Katschinka, L. 2003. On language, legal skills and structures that should be utilised in legal interpreting and translation. In E. Hertog (ed.) Aequalitas: Equal access to justice across language and culture in the EU. Antwerp: Lessius Hogeschool. pp. 59-68.

Khoon, W.F. 1990. Court interpreting in a multiracial society: The Malaysian experience. In D. Bowen and M. Bowen (eds.) Interpreting: Yesterday, today and tomorrow. Binghamton: State University of New York. pp. 108-116.

Moeketsi, R. 1999. Discourse in a multilingual and multicultural courtroom: A court interpreter's guide. Pretoria: JL van Schaik. 
Moser-Mercer, B. 1996. Quality in interpreting: Some methodological issues. The Interpreters' Newsletter 7: 43-55.

Myers-Scotton, C. 1993. Social motivations for codeswitching: Evidence from Africa. Oxford: Clarendon Press.

O'Leary, Z. 2005. Researching real word problems: A guide to methods of inquiry. London: Sage Publications.

Ostarhild, E. 2001. Continuing professional development. In E. Hertog (ed.) Aequitas: Access to justice across language and culture in the EU. Antwerp: Lessius Hogeschool. pp. 67-73.

Richards, J.C and R. Schmidt. 2002. Longman dictionary of language teaching and applied linguistics. London: Longman.

Schweda-Nicholson, N. 1989. Ad hoc court interpreters in the United States. Meta XXXIV (4): 711-723.

South African Constitution. 1996. Available online: http://www.ch.up.ac.za/hr doc/countries/ doc/SA_english.pdf (Accessed 16 February 2008).

Walliman, N. 2006. Social research methods. London: Sage Publications.

Wiersinga H.C. 2003. Justice, not just us. Prologomena towards an analysis of communication problems in criminal proceedings. In E. Hertog (ed.) Aequalitas: Equal access to justice across language and culture in the EU. Antwerp: Lessius Hogeschool. pp. 21-32. 